\title{
COULD EARLY WARNING SYSTEMS HAVE HELPED TO PREDICT THE SUB PRIME CRISIS?
}

\author{
E Philip Davis and Dilruba Karim ${ }^{1}$ \\ Brunel University and NIESR \\ London
}

\begin{abstract}
One of the features of the sub-prime crisis, that began in August 2007, was its unexpected nature. It came as a surprise not only to most financial market participants but also in some degree to the policy community. In this context, we seek to assess whether early warning systems based on the logit and binomial tree approaches on the UK and US economies could have helped to warn about the crisis. We also consider a "check list approach" of indicators based on history. Although not all of the complementary approaches are successful, we contend that our work suggests that a broadening of approaches of macroprudential analysis is appropriate.
\end{abstract}

Keywords: Sub prime crisis, early warning, financial instability, macroprudential analysis JEL classification: E44, E58

\footnotetext{
${ }^{1}$ Davis Brunel University, Uxbridge, Middlesex, UB8 3PH and NIESR. e-mail: e_philip_davis@msn.com, Karim, Brunel University, Uxbridge, Middlesex, UB8 3PH. e-mail: dilruba.karim@brunel.ac.uk
} 


\section{Introduction}

One of the features of the sub-prime crisis, that began in August 2007, was its unexpected nature. It came as a surprise not only to most financial market participants but also in some degree to the policy community. The latter is a paradox, since there has been extensive research both in universities and in policy institutions, notably since the Asian crisis of 1997, into the causes and predictors of financial crises. Furthermore, central banks and international organisations such as the IMF have for some years been producing and developing "macroprudential analyses" and publishing their current findings in "Financial Stability Reviews". The latter are designed specifically to highlight current risks to financial stability as seen by the authorities, and to recommend appropriate evasive action by financial institutions under their remit.

In this context, we seek to assess whether some of the early warning systems that have been developed in the literature (but rarely applied to banking crises) could have helped the prediction of the crisis. We specifically use the logit and binomial tree approaches on the UK and US economies, approaches that as described in Davis and Karim (2008) and Karim (2008) have been successful in predicting a majority of banking crises in emerging markets and advanced countries in 1970-2003. We also consider whether a simple indicator/checklist approach as in Davis $(1995,1999,2003)$ could have helped to warn about the crisis.

The article in structured as follows. In section 1 we look at the FSRs before the crisis for the major institutions (Bank of England, IMF, ECB) to see to what extent the crisis was predicted. In Section 2 we outline the early warning system methodologies. Section 3 shows the main results, while Section 4 briefly considers the "check list approach" of indicators based on history. Section 5 concludes.

\section{Financial stability reviews and the sub-prime crisis}

Hindsight is always beneficial and it is easy to criticise those undertaking the difficult task of macroprudential surveillance. This is not the aim of the current section. Rather, we seek to assess the degree to which the crisis was foreseen only with a view to considering whether successful early warning systems could have been a useful supplement to conventional macroprudential surveillance. We examine predictions in the FSRs of the IMF, ECB, Bank of England and the BIS for the Spring of 2007 for indications of concern over an imminent crisis. We only focus on the main policy messages in the overview/executive summaries.

In its Global Financial Stability Report for April 2007, the IMF suggested there was a "strong foundation for global financial stability" but suggested that some market developments "warranted attention". They did see short-term risks from "possible spillovers from a deterioration in credit quality in the US subprime mortgage markets", that could spread to "structured mortgage credit products" but felt that "financial effects may also be contained". Other risks seen were related to rises in corporate leverage due to buyouts, and rapidly rising capital inflows to emerging markets, but it was concluded that "none of the individually identified risks by themselves threaten financial stability" although it was noted that "a sustained rise in volatility could perturb a wide range of markets", with a build-up of positions that could result in a disorderly correction when conditions change.

In the ECB Financial Stability Review for June 2007 it was suggested that minor turmoil in March and April 2007 "reaffirm concerns about pre-existing vulnerabilities". They noted evidence of direct exposures of some European institutions to the US sub prime market and the more general possibility that the "crisis" in the US sub prime mortgage market could 
deepen and spread to other markets". Growth in credit risk transfer (CRT) instruments were seen as partly underlying an increase in liquidity, but the risk was noted that liquidity may hide a "slippage in risk assessment standards", and that history shows that "liquidity can vanish abruptly from financial markets when investor uncertainty and risk aversion rise". Concerns were also expressed over leverage in the Euro area corporate and household sectors, although banks' solvency was seen to be comfortable relative to regulatory requirements. Overall, they concluded that the most likely prospect is that "financial system stability will be maintained in the period ahead" with the likelihood of significant challenges "not high at present". However, "the vulnerability of the financial system to an abrupt and unexpected loss of market liquidity appeared to be increasing", and concerns were raised about the effect on buyers of structured products "if the CRT market were to be subjected to severe stress, possibly triggered by an adverse turn in the credit cycle".

The Bank of England in its Financial Stability Report for April 2007, while asserting that the "UK financial system remains highly resilient" noted that macroeconomic stability and competition in the financial sector have "encouraged a further increase in risk taking", which had in turn led to a further development in credit risk transfer markets. The experience of the sub-prime market was seen as illustrative of risks if a "more significant market such as corporate credit" were to deteriorate. Risks were of weakened credit risk assessment, impaired risk monitoring and impaired market liquidity leading to "warehousing risk" as institutions piled up loans they were unable to securitise. These were held to compound pre-existing risks arising from high asset prices and vulnerabilities in risk premia, corporate debt and market infrastructure, as well as complacency by LCFIs over low volatility. There was seen to be a risk of unwinding of low risk premia, triggering a pickup in corporate defaults, an unwinding of leveraged positions in corporate credit markets and consequently lower market liquidity and further falls in asset prices.

In its Annual Report for 2006-7 released in June 2007 (technically not an FSR, but covering financial stability concerns as part of its remit), the BIS noted that an "ever increasing number of economic and financial variables have been observed to deviate significantly from what might be deemed traditional norms" which might not be sustainable. They highlighted that the world seems "awash with liquidity" with mortgage credit available on unprecedented terms. Low risk free rates and intense competition were seen as underlying a high appetite for risk, but also the misperception of risk due to lack of due diligence in the originate and distribute model - related in turn to principal agent problems. Concerns were expressed about "irrational exuberance" and risk of overpricing assets, that might turn to undershooting of prices, if liquidity dries up and correlations of asset prices rise as has been seen " many times in the past". Such a pattern could give rise to risks for banks (warehousing risk) but also to holders of CRT instruments, especially hedge funds. More generally the BIS argued that there were signs of a fundamental change in the credit cycle - as took place shortly afterwards. They concluded that "a tail event affecting the global economy might at some point have much higher costs than is commonly supposed". Furthermore, they discussed issues that would arise in that case, including the possibility that policymakers would need to restructure the banking system and close failing banks, not merely infuse liquidity. Excessive debt and investment needs to be eliminated and not allowed to be a drag on the economy as in Japan in the 1990s.

It is clear that the authorities did foresee a number of features of the crisis, but not the extent of the crisis. Furthermore, in their headline sections, it is notable that none of the reports highlighted the conduits and special investment vehicles (SIVs) that were a key feature of the crisis. None foresaw the collapse of the interbank market or the overall magnitude of the 
effects from the sub-prime crisis alone. None considered possible links from financial instability to the real economy that are being seen now.

We now go on to consider whether statistical early warning systems could have supplemented qualitative analyses. However, we note in advance that the US subprime episode, associated with interbank liquidity risk, is a classic example of the distinctiveness of crisis episodes; each event is context dependent and driven by the non-linear interactions between a particular set of variables. Although some of these variables may be common to other crises, the particular thresholds at which they interact may differ and consequently the types and magnitudes of risks they generate will vary. Hence, early warning systems were unlikely even ex ante to predict any crisis in all its features. All they can do is to highlight increased vulnerability of the system.

\section{$2 \quad$ Early warning systems - Binary Recursive Trees and Logit Models}

To examine the extent to which the US subprime crisis was predicted by ex ante macroeconomic and financial data, we utilise two different early warning system approaches. One is the "traditional" multivariate logit method and the other is the binary recursive tree (BRT) technique. The latter approach is a new tool for banking crisis prediction, which has previously been applied to systemic banking crises only by Duttagupta and Cashin (2008).

Once a baseline model is constructed, data prior to the actual crisis event can be used to generate a predicted banking crisis probability; if the crisis has not already materialised, this generates a pure prediction otherwise, as in the case of our experiment, the probability serves to demonstrate the difference between the ex-ante crisis probability and the ex-post crisis probability value of one.

The logit approach is ideally suited to predicting a binary outcome $(1=$ banking crisis, $0=$ no banking crisis) using multiple explanatory variables selected on the basis of their theoretical or observed associations with banking crises. One advantage of the logit approach is the fact that it has been "tried and tested" in the banking crisis literature (see Demirguc-Kunt and Detragiache (1998 and 2000) and Davis and Karim (2008)) hence it is possible to compare the importance of different indicators in several studies. The logistic approach is also parametric, generating confidence intervals attached to coefficient values and their significance. On the other hand the logit coefficients are not intuitive to interpret (see below) and they do not reflect the threshold effects that may be simultaneously exerted by other variables. Nevertheless, we contend that crisis predictions generated by logit models are able to significantly improve the policy maker's arsenal against banking crises; assuming intervention against crises is informed on the basis of correct logit signals, taxpayers funds are less likely to be wasted than if no intervention had occurred because the bailout costs associated with non-averted crises are likely to be higher than intervention costs (see Karim, $\left.2008^{\mathrm{a}}\right)$.

We propose the BRT technique as an alternative because of its ability to detect interactions between multiple explanatory variables. Moreover, this technique is able to discover nonlinear variable interactions, making it especially applicable to large banking crises datasets where many cross-sections are necessary to generate enough banking crisis observations and numerous factors determine the occurrence of systemic failure.

An important feature of this non-parametric technique is that no specific statistical distribution needs be imposed on the explanatory variables (Katz, 2006). It is also not necessary to assume all variables follow identical distributions or that each variable adopts the 
same distribution across cross-sections. Clearly, this is an advantage when analysing banking crises since we cannot assume macro variables (such as real interest rates) and institutional variables (such as deposit insurance) follow identical distributions across time or across countries. Although logistic regression does not require variables to follow any specific distribution, in Davis and Karim (2008) it was shown that standardising variables displaying heterogeneity across countries improved the predictive performance of logit models.

Logistic regressions are also sensitive to outlier effects (Congdon, 2003), yet it is precisely the non-linear threshold effects exerted by some variables that could generate anomalous values in the data. ${ }^{2}$ In low risk, stable regimes, variables may conform to a particular distribution which subsequently jumps to a regime of financial instability. Non-parametric BRTs should handle such data patterns better than logistic regressions.

Finally, the BRT is extremely intuitive to interpret. The model output is represented as a tree which is successively split at the threshold values of variables that are deemed as important contributors to banking crises. The multivariate logit and BRT methodologies are described in more detail below.

\subsection{The Multivariate Logit Approach}

Demirguc-Kunt and Detragiache (1998) used the multivariate logit technique to relate the probabilities of systemic banking crises to a vector of explanatory variables. The banking crisis dependent variable is represented by a binary banking crisis dummy which is defined in terms of observable stresses to a countries' banking system, e.g. ratio of non-performing loans to total banking system assets exceeds $10 \%{ }^{3}$. Demirguc-Kunt and Detragiache (2005) updated the banking crises list to include more years. We continue to utilise this version of the banking crisis dummy and henceforth refer to it as DD05.

The logistic cumulative distribution relates the probability that the dummy takes a value of one to the logit of the vector of $n$ explanatory variables:

$$
\operatorname{Prob} \gamma_{\text {it }}=1=F \beta X_{\text {it }}=\frac{\mathrm{e}^{\beta \prime} \mathrm{X}_{\text {it }}}{1+\mathrm{e}^{\beta^{\prime} \mathrm{X}_{\mathrm{it}}}}
$$

where $\mathrm{Y}_{\mathrm{it}}$ is the banking crisis dummy for country $\mathrm{i}$ at time $\mathrm{t}, \beta$ is the vector of coefficients, $\mathrm{X}_{\mathrm{it}}$ is the vector of explanatory variables and $\mathrm{F}\left(\beta \mathrm{X}_{\mathrm{it}}\right)$ is the cumulative logistic distribution. The log likelihood function which is used to obtain actual parameter estimates is given by:

$$
\log _{e} L=\sum_{i=1}^{n} \sum_{t=1}^{T} \mathbf{k}_{i t} \log _{e} F \boldsymbol{\beta}^{\prime} X_{i t}+\mathbf{Q}-Y_{i t} \log _{e} \mathbf{Q}-F \boldsymbol{\beta}^{\prime} X_{i t}=
$$

Although the sign on the coefficients are easily interpreted as representing an increasing or decreasing effect on crisis probability, the values are not as intuitive to interpret. Equation (2) shows the coefficients on $X_{i t}$ are not constant marginal effects of the variable on banking crisis probability since the variable's effect is conditional on the values of all other

\footnotetext{
${ }^{2}$ This is distinct from normal variation in the data which derives from the probability distributions of the explanatory variables and is required to explain the dependent variable.

${ }^{3}$ Their actual criteria are: the proportion of non-performing loans to total banking system assets exceeded $10 \%$, or the public bailout cost exceeded $2 \%$ of GDP, or systemic crisis caused large scale bank nationalisation, or extensive bank runs were visible and if not, emergency government intervention was visible.
} 
explanatory variables at time t. Rather, the coefficient $\beta_{i}$ represents the effect of $X_{i}$ when all other variables are held at their sample mean values. This makes the detection of non-linear variable interactions difficult, unlike the BRT technique which we outline below.

\subsection{The Binary Recursive Tree Approach}

The statistical component of this study uses a proprietary software package known as "CART" to construct the BRT. We give a brief outline of the methodology here; a fuller explanation can be found in Breimen at al (1984) and Steinberg and Colla (1995) and economic applications can be found in Duttagupta and Cashin (2008) who examined banking crises, Manasse et al (2003) who examined sovereign debt crises and Ghosh and Ghosh (2002) who examined currency crises.

The BRT process analyses a sample of data to reveal the particular value of the explanatory variable that best explains the dependent variable. Hypothetically, it could be established that the level of real GDP growth best distinguishes between crisis and non-crisis episodes across the entire sample. CART would then search for the exact threshold level of GDP growth that separates crises from tranquil periods. Assuming this "splitting value" is 4\%, all data will be split into two child nodes with observations associated with GDP growth $<=4 \%$ in the left child node and remaining observations associated with GDP growth $>4 \%$ in the right child node. If low GDP growth were detrimental to banking stability, we would expect the left child node to be concentrated with banking crisis observations relative to the right node; the CART algorithm will search through all possible splitting values of all explanatory variables to find the best discriminator between crises and non-crises across the entire sample. Once this "primary splitter" has been obtained, CART will apply the same procedure to further split the observations located in the two child nodes and in doing so will generate the BRT. This is schematically represented in figure 1 where the primary splitter is $X_{1}$ and the corresponding threshold value is $\mathrm{V}_{1}{ }^{*}$. Subsequent splitter variables (and their threshold values) are given by $\mathrm{X}_{2}\left(\mathrm{~V}_{2}\right)$ and $\mathrm{X}_{3}\left(\mathrm{~V}_{3}\right)$; these values are used to partition the 72 crises in the sample.

\begin{tabular}{l}
\hline Figure 1: Schematic \\
Diagram of Binary \\
Recursive Tree (BRT)
\end{tabular}

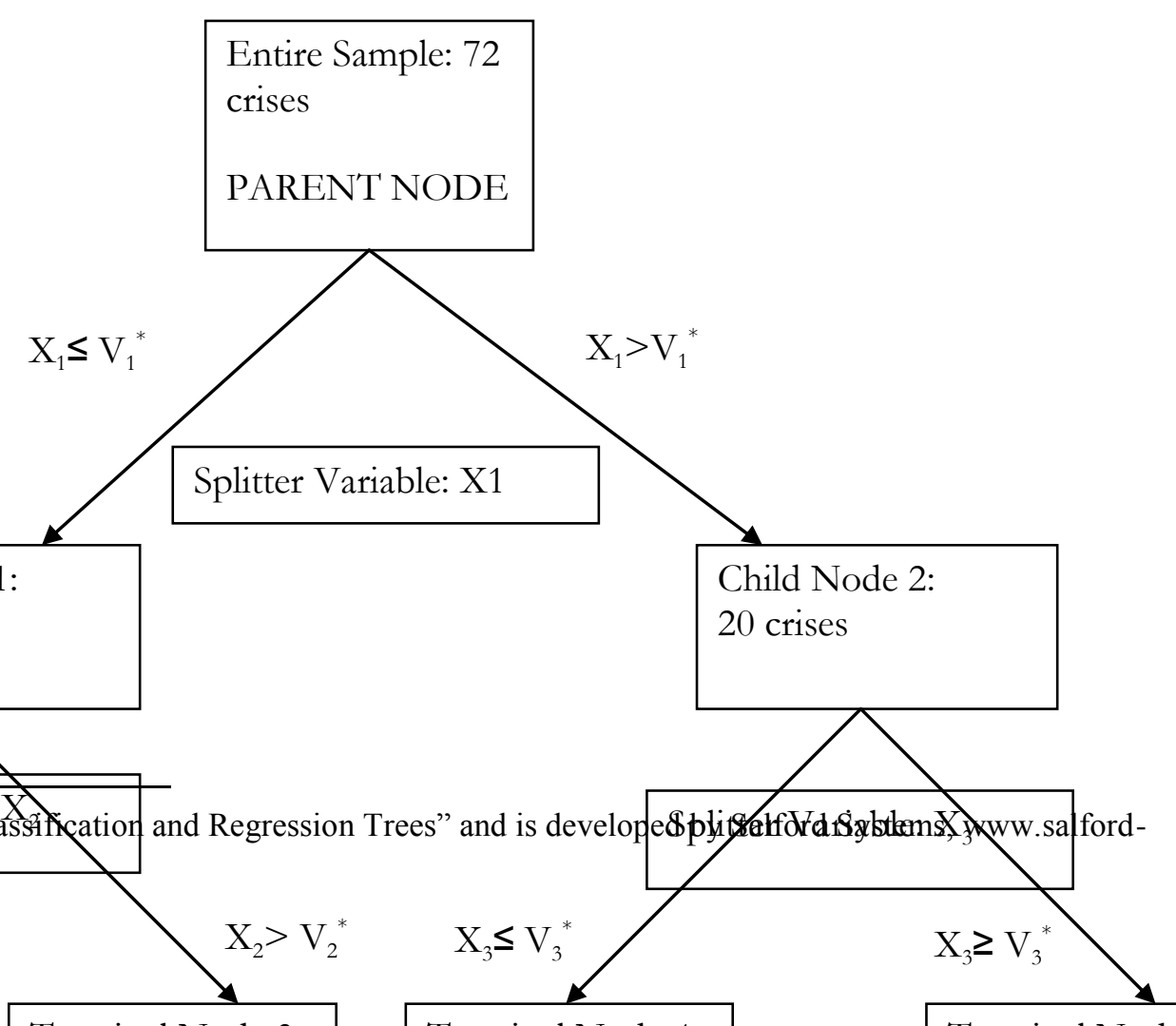

Terminal Node 3:

Terminal Node 4: 
The choice between two potential splitters is made on the basis of their comparative abilities to increase node purity, i.e. to concentrate the node further with one type of observation. The change in impurity $\omega_{i}^{-}$that arises from splitting (s) the data at a node $(\mathrm{t})$ is defined as:

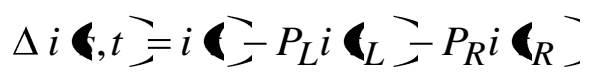

where $i \boldsymbol{\complement}_{-}, i{\boldsymbol{\mathbb { L } _ { L }}}_{L_{-}}$and $i{\boldsymbol{\boldsymbol { } _ { R }}}_{R_{-}}$are the impurities associated with each existing node and the left and right child nodes respectively and $P_{L}$ and $P_{R}$ are the probabilities of sending an observation in the left and right nodes respectively. To quantify the degree of impurity, we use a criterion called the Gini measure, which is applicable to binary dependent variables (Steinberg and Golovnya, 2007). The Gini measure is given by:

$$
i \mathbf{Q}=\sum_{i, j} c \mathbb{Q} j ; P \mathbb{Q}\left|t_{j} P \mathbf{8}\right| t_{-}^{-}
$$

where $c \mathbb{j}$ is the cost of misclassifying a non-crisis event given that it is a crisis event, $p\left(j \mid t^{-}\right.$is the conditional probability that an observation takes class $j$ given that it lies in node $\mathrm{t}$ and $p<\mid t^{-}$is the conditional probability that an observation takes class $i$ given that it lies in node $\mathrm{t}$ (where $j=$ crisis and $i=$ no crisis). We next describe the data sample we use to estimate the logit and BRT models.

\section{Applying the models to the US in the 2000s}

\subsection{The Data Sample}

Our sample consists of 105 countries covering the years 1979-2003. According to their association with banking crises, and as highlighted in previous studies, we select 12 explanatory variables (see Davis and Karim, 2008). These 12 variables are macroeconomic, financial and institutional ${ }^{5}$ and are listed in Box 1 . The DD05 banking crisis dummy yields 72 systemic banking crisis ${ }^{6}$ episodes across the entire sample of which 7 are in advanced (OECD) countries ${ }^{7}$ and 65 in emerging markets.

\begin{tabular}{|l|l|}
\hline Box 1: List of Variables (with variable key) \\
\hline \multirow{4}{*}{$\begin{array}{c}\text { Macroeconomic } \\
\text { Variables }\end{array}$} & 1. Real GDP Growth (\%) (GDP) \\
\cline { 2 - 2 } & 2. Change in Terms of Trade (\%) (TOT) \\
\cline { 2 - 2 } & 3. Nominal Depreciation (\%) (DEP) \\
\cline { 2 - 2 } & 4. Real Interest Rate (\%) (RIR) \\
\cline { 2 - 2 } & 5. Inflation (\%) (INF) \\
\cline { 2 - 2 } & 6. Fiscal Surplus/ GDP (\%) (BB) \\
\hline \multirow{4}{*}{ Financial Variables } & 7. M2/ Foreign Exchange Reserves (\%) (M2RES) \\
\cline { 2 - 2 } & 8. Credit to Private Sector/ GDP (\%) (CREDGDP) \\
\cline { 2 - 2 } & 9. Bank Liquid Reserves/ Total Bank Assets (\%) (RES2ASS) \\
\hline
\end{tabular}

\footnotetext{
${ }^{5}$ All data is obtained from the IMF International Financial Statistics Database or the World Bank Development Indicator set. See Demirguc-Kunt and Detragiache (1998) for a detailed sourcing of data.

${ }^{6}$ This excludes the two out-of-sample banking crises which are tested later in this study.

${ }^{7}$ Finland (1991), Italy (1990), Japan (1992), Norway (1987), Portugal (1986), Sweden (1990) and USA (1980).
} 


\begin{tabular}{|l|l|}
\hline & 10. Real Domestic Credit Growth (\%) (DCG) \\
\hline \multirow{2}{*}{ Institutional Variables } & 11. Real GDP per Capita (GDPCAP) \\
\cline { 2 - 2 } & 12. Deposit Insurance (binary dummy) (DI) \\
\hline
\end{tabular}

The data are partitioned into a 1979-1999 sample which is used along with the DD05 banking crisis dummy to construct two baseline models: a logit model (called second tier logit (1)) and a BRT model (called second tier tree (2)). These baseline models are then applied to out of sample data for the years 2000 - 2007 for the USA to see if the sub-prime episode was detectable in advance. As a comparison, we also apply the two models to out of sample data for the UK $(2000-2007)$.

\subsection{Results: Baseline Tree}

Box 2 gives the results for the second tier logit (1) model whilst Figure 2 shows the second tier tree (2) including the splitting variables, their corresponding threshold values and the partitioning of crisis and non-crisis observations in each node.

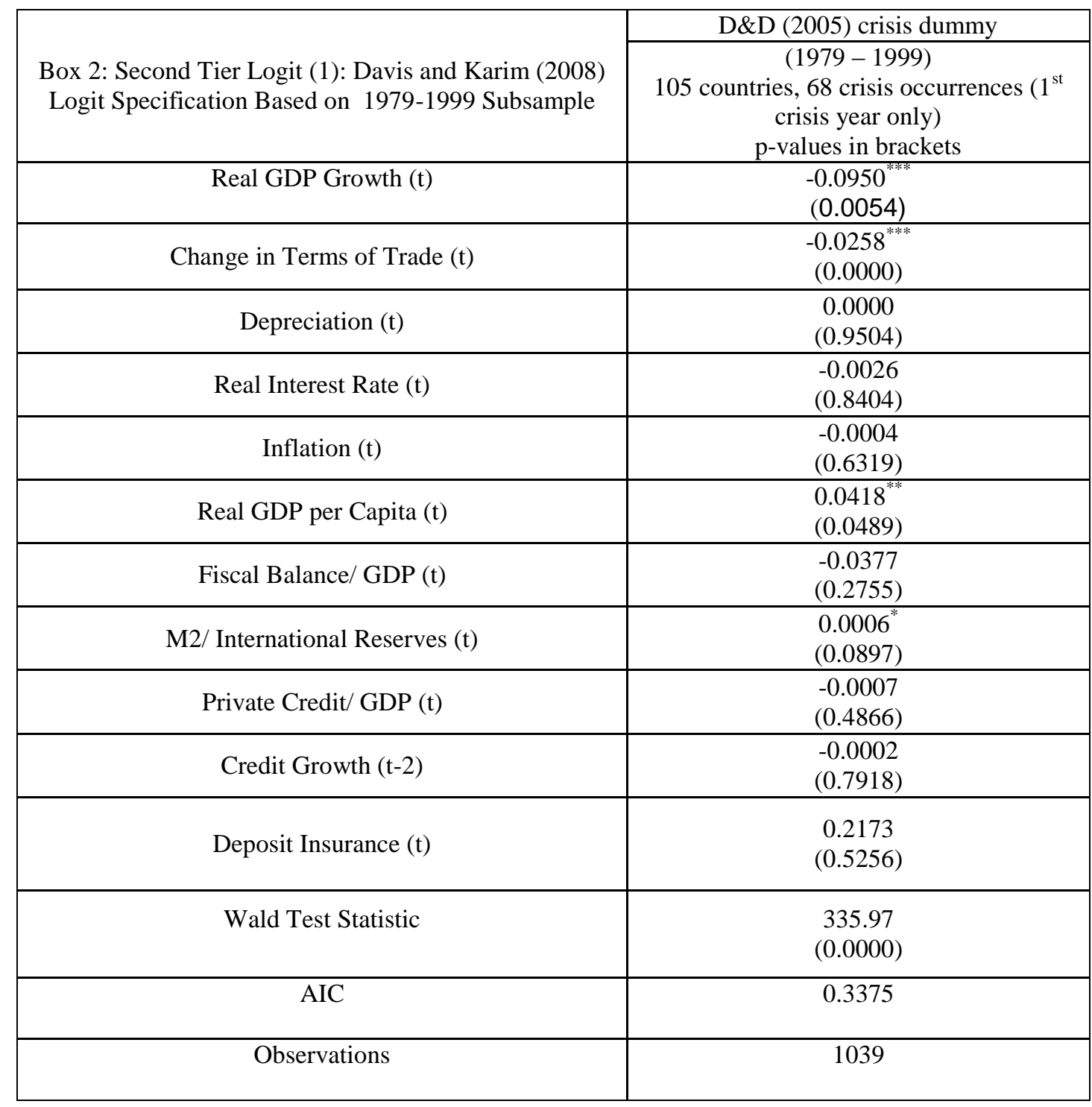




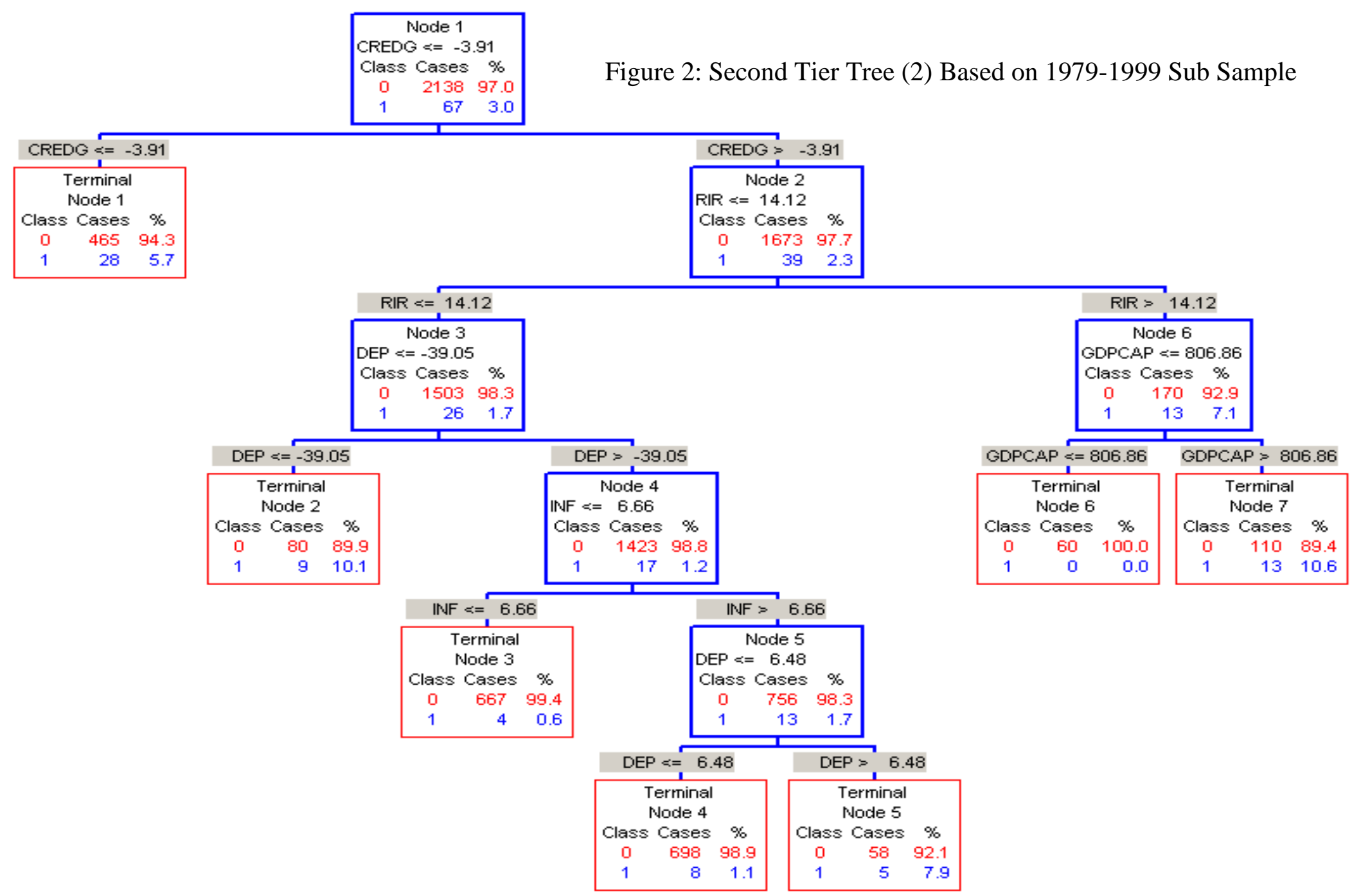


The results of logit specifications have been discussed extensively in Davis and Karim (2008); suffice to note that only a subset of the Demirguc-Kunt and Detragiache (2005) coefficients are significant determinants of banking crises in our re-estimate. These are real GDP growth, terms of trade, real GDP per capita and M2/reserves. Neither private credit/GDP, credit growth nor a deposit insurance dummy are significant. We now discuss in more detail the second tier tree (2) before applying both models to out-of-sample data for the USA.

Across the entire sample, the tree selects real domestic credit growth as the main discriminator between crisis and non-crisis events; countries where credit contracts by more than $4 \%$ are over twice as likely to experience banking crisis than countries where credit contraction is less severe or where credit growth occurs. For the latter class of countries real interest rates are the next most important splitter variable; interest rates in excess of $14 \%$ are associated with higher crisis likelihood and this is worsened if GDP per capita (which may be correlated with banking sector innovations) exceeds $\$ 806$.

If countries' real interest rates are below 14\%, the additional impact of currency depreciation in excess of $39 \%$ substantially increases crisis probability (from $1.7 \%$ to $10.1 \%)$. In combination with lower $(<14 \%)$ real interest rates, currency depreciation of less than $39 \%$ reduces crisis probability to $1.2 \%$ but this is offset by an inflation rate higher than $6.7 \%$. This probability is worsened substantially if the currency appreciates by more than $6.5 \%$; in this case the probability of banking crises rises to $8 \%$ (terminal node 5). We next apply this tree model and the logit regression to outof-sample data for the USA.

\subsection{Results: Predicting the US Sub Prime Crisis}

Box 3: Predicted Probabilities (\%) of Banking Crisis in the US

\begin{tabular}{|c|c|c|}
\hline & $\begin{array}{c}\text { Second Tier Logit } \\
(1)\end{array}$ & $\begin{array}{c}\text { Second Tier Tree } \\
(2)\end{array}$ \\
\hline 2000 & 1.462 & 0.596 \\
\hline 2001 & 1.920 & 0.596 \\
\hline 2002 & 1.480 & 0.596 \\
\hline 2003 & 1.417 & 0.596 \\
\hline 2004 & 1.078 & 0.596 \\
\hline 2005 & 1.236 & 0.596 \\
\hline 2006 & 1.278 & 0.596 \\
\hline 2007 & 0.985 & 0.596 \\
\hline
\end{tabular}




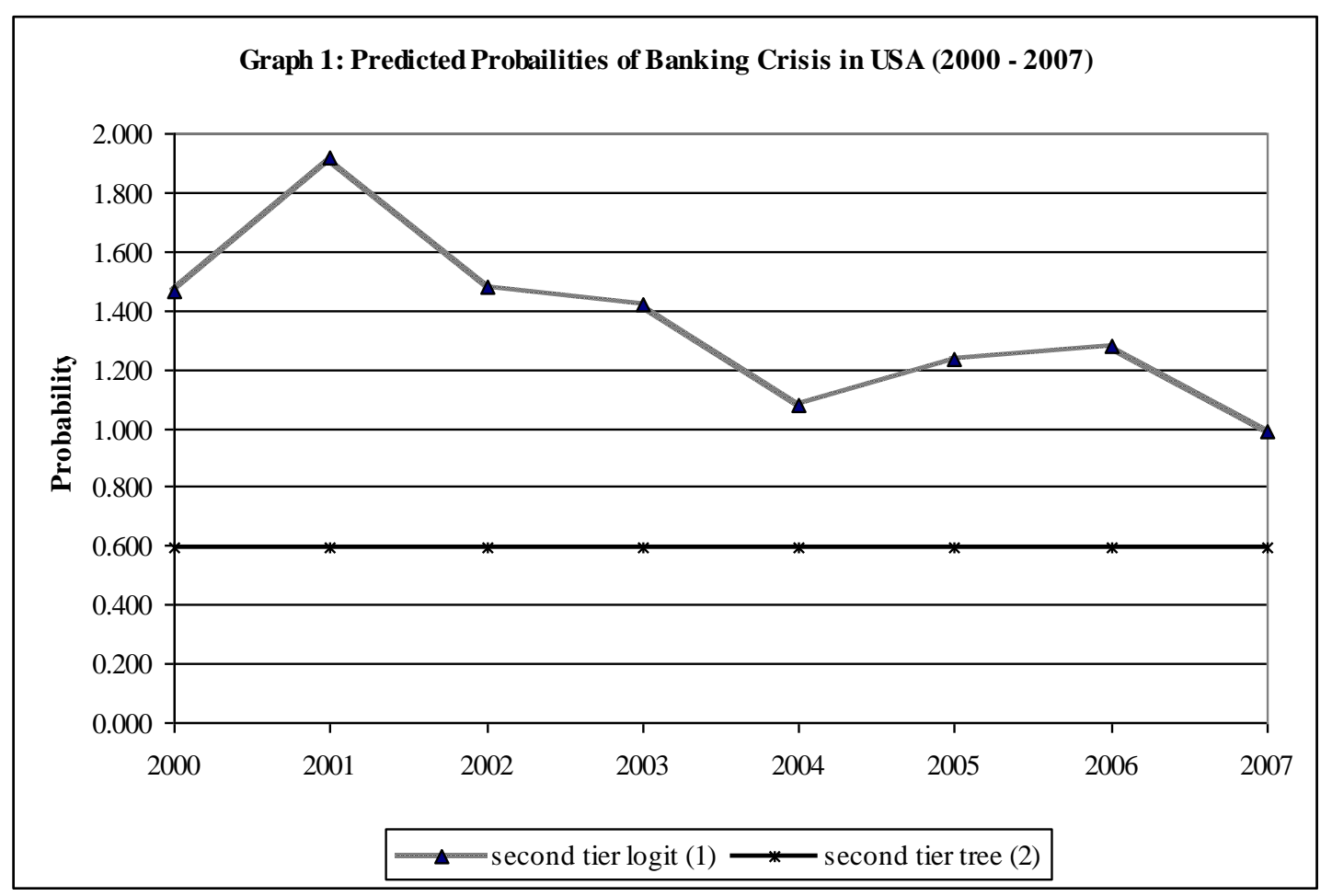

Box 3 and the corresponding Graph 1 show the predicted crisis probabilities generated by the two models. The BRT approach yields a low crisis probability $(0.6 \%)$ which does not change in the run up to the sub-prime episode; the placement of all the US observations into a common node results in a constant crisis probability (see section 2.2). The BRT algorithm chose to place every observation in node 3 indicating the following dynamics: low credit contraction (or positive credit growth) combined with real interest rates below $14 \%$. The other pathways in the second tier tree (2) were therefore not applicable in the US case.

By construction we allowed the sub-prime crisis to start in 2007, so that this is the only year when the DD05 dummy takes a value of 1 . On this basis, the out-of-sample probability of crisis $=12.5 \%^{8}$ so that the BRT was correctly able to classify $87.5 \%$ of observations, assuming that a crisis probability of $0.6 \%$ is interpreted to mean no crisis will occur. This implies that within the category of crisis classification, the BRT was $100 \%$ unsuccessful since the ex-ante crisis probability of $0.6 \%$ fails to match the ex-post probability of 1 . Within the category of non-crisis classification, the BRT model scored $100 \%$ success; the model's overall ability to correctly classify the outof-sample data was therefore $87.5 \%$.

The second tier logit model (1) actually predicts the highest chance of banking crisis in 2001 at almost $2 \%$ (linked to the peak of the equity bubble and the start of the bear market). The predicted probabilities decline until 2004 (1.08\%) but interestingly begin to rise after this with another peak probability occurring in 2006 (1.28\%). However, the logit model then predicts the lowest crisis probability in $2007(0.99 \%)$. Given the failure to identify the start of crisis in 2007 and the over identification of crisis episode during the previous years, the logit approach slightly underperforms relative

\footnotetext{
${ }^{8}$ For observations for 2000-2007, a banking crisis in one year yields an in sample crisis probability of $1 / 8=12.5 \%$.
} 
to the BRT approach, although if the policy maker interprets the 2000-2006 probabilities to mean that no crisis will occur, the logit model has exactly the same overall performance as the BRT.

Interestingly, in-sample, the second tier tree (2) shows a heightened crisis probability for the USA during the years 1986 - 1989 and 1990 - 1992 broadly in line with the Savings and Loans episode and the "Credit Crunch" (albeit only signalling an 8\% chance of a crisis). In contrast, the second tier logit (1) model fails to signal potential crises during the same years; the generated probabilities are not significantly different from zero. Graph 2 shows the in-sample crisis probabilities generated by the second tier tree (2).

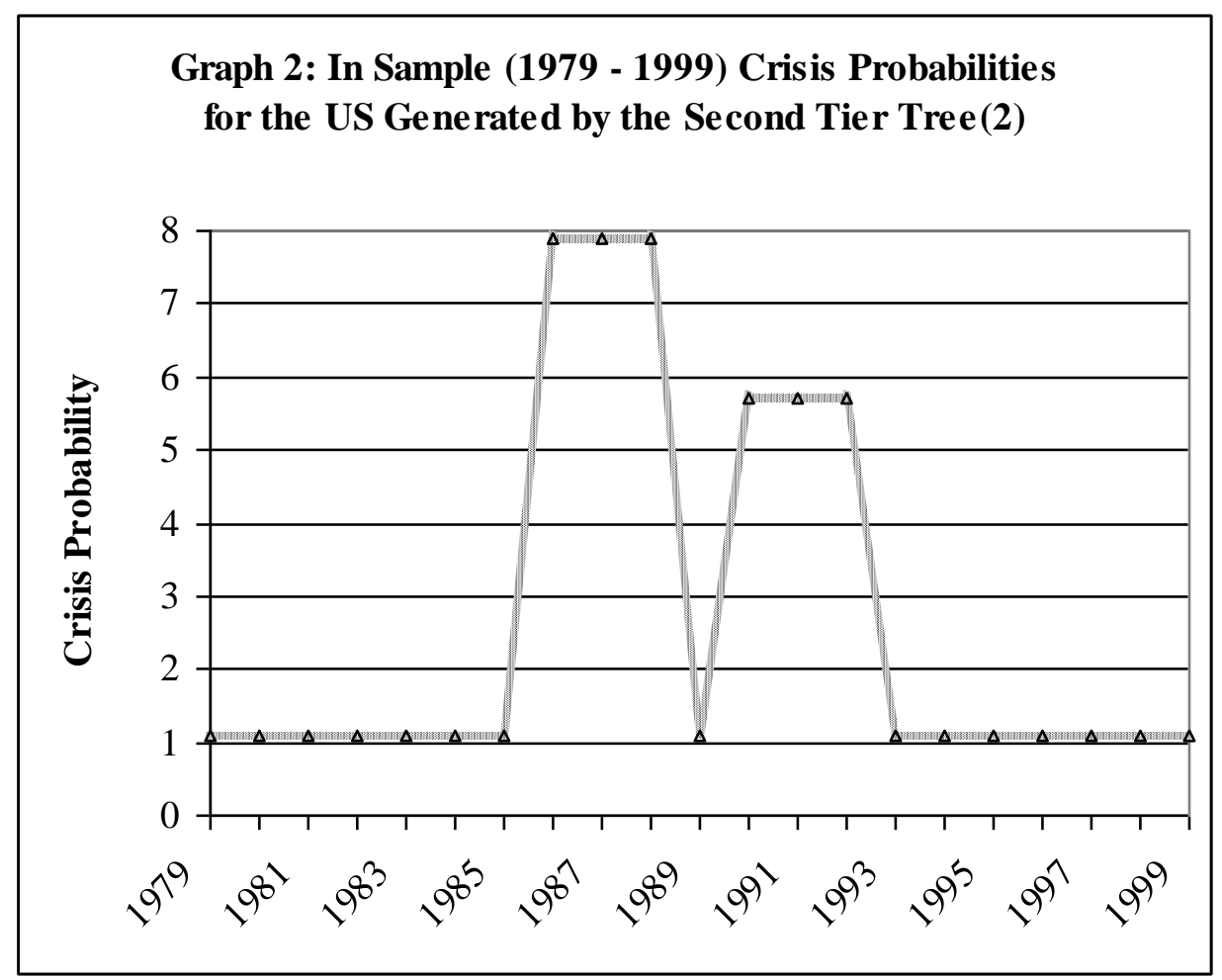

The failure of this second tier tree (2) to detect the sub-prime crisis underlines the fact that it was a unique episode which was not contained in the information carried by exante macroeconomic indicators. To further illustrate this point, we show the out-ofsample $(2000$ - 2007) predicted crisis probabilities for the UK in Box 4; again the second tier tree (2) evaluates the probability of banking crisis as under $1 \%$ and unchanging in the run up to the crisis event ${ }^{9}$. The information contained in the macroeconomic data foretells no major aberrant behaviour in the fundamentals and consequently the tree places all UK observations in one node associated with a low crisis probability. On the other hand, the second tier logit (1) model is able to detect an increase in crisis probability during the years $2000-2005$ although the probability declines during 2006 and 2007.

\footnotetext{
${ }^{9}$ As with the US, we set the start date of the UK banking crisis in 2007.
} 
For further information, we provide comparative out-of-sample banking crisis predictions for 5 OECD countries in the Appendix (Graph A.1) which are based on the two model specifications we use in this study alongside two additional logit and tree specifications detailed in Karim $\left(2008^{\mathrm{b}}\right)$. For the majority of countries, there is no appreciable increase in crisis probabilities in the two years preceding the sub prime episode; in some cases there are actual decreases in probabilities.

Box 4: Predicted Probabilities (\%) of Banking Crisis in the UK
\begin{tabular}{|c|c|c|}
\hline & $\begin{array}{c}\text { Second Tier Logit } \\
(1)\end{array}$ & $\begin{array}{c}\text { Second Tier Tree } \\
(2)\end{array}$ \\
\hline 2000 & 5.04 & 0.60 \\
\hline 2001 & 6.41 & 0.60 \\
\hline 2002 & 6.88 & 0.60 \\
\hline 2003 & 7.57 & 0.60 \\
\hline 2004 & 5.37 & 0.60 \\
\hline 2005 & 5.91 & 0.60 \\
\hline 2006 & 3.23 & 0.60 \\
\hline 2007 & 3.35 & 0.60 \\
\hline
\end{tabular}

Although the results show the sub-prime crisis was not clearly identifiable by the logit and BRT models we use, we contend that this does not make the models redundant; they should be assessed in the light of the following points. Firstly, in Davis and Karim (2008) we highlighted the possibility of type II errors being generated by the logit early warning system due to crisis over prediction (whereby the model classifies non-crisis observations as crisis observations). Unlike equation (4), the maximum likelihood function (equation 2) does not contain any $c\left(j-j_{-}^{-}\right.$term (which is the cost of misclassifying non-crises events as crises) and so the logit model does not explicitly penalise such misclassifications ${ }^{10}$.

Secondly, the explanatory variables we use are broad in the sense that subtle risks associated with banking instability may not be detected (see graph 3). For example, if there is no major shift in monetary policy, credit growth or the overall macroeconomic environment, the early warning system may be unable to detect banking vulnerabilities. Our underlying logit model is a global model which relies on readily available macro data for developed and developing countries; and as shown in the Appendix most crises were in developing countries, where crises may have a different pattern to OECD countries. However it would be possible to construct a regional model for advanced countries using both techniques that would enable more

\footnotetext{
${ }^{10}$ General goodness-of-fit tests are available to compare the fitted probabilities of crises to actual crises probabilities; they do not discriminate between types of misclassification (crises versus non-crises). For a policy maker who has an aversion to unnecessary intervention against banking crisis, the cost of a false alarm may be high but she would have to manually control for this by setting a high cut-off probability threshold (see Karim, 2008 ${ }^{\mathrm{b}}$ ).
} 
bank specific data as inputs, such as credit default swap rates for major OECD banks or LIBOR rates. This may improve the detection of banking sector risks typical of advanced countries and make episodes such as the US sub-prime crisis better detectable. Possibly a more serious problem is that the sub prime was one of the first global crises, making it hard to capture by regressions focused on crises in individual countries. At least, further research could include cross country as well as withincountry variables.

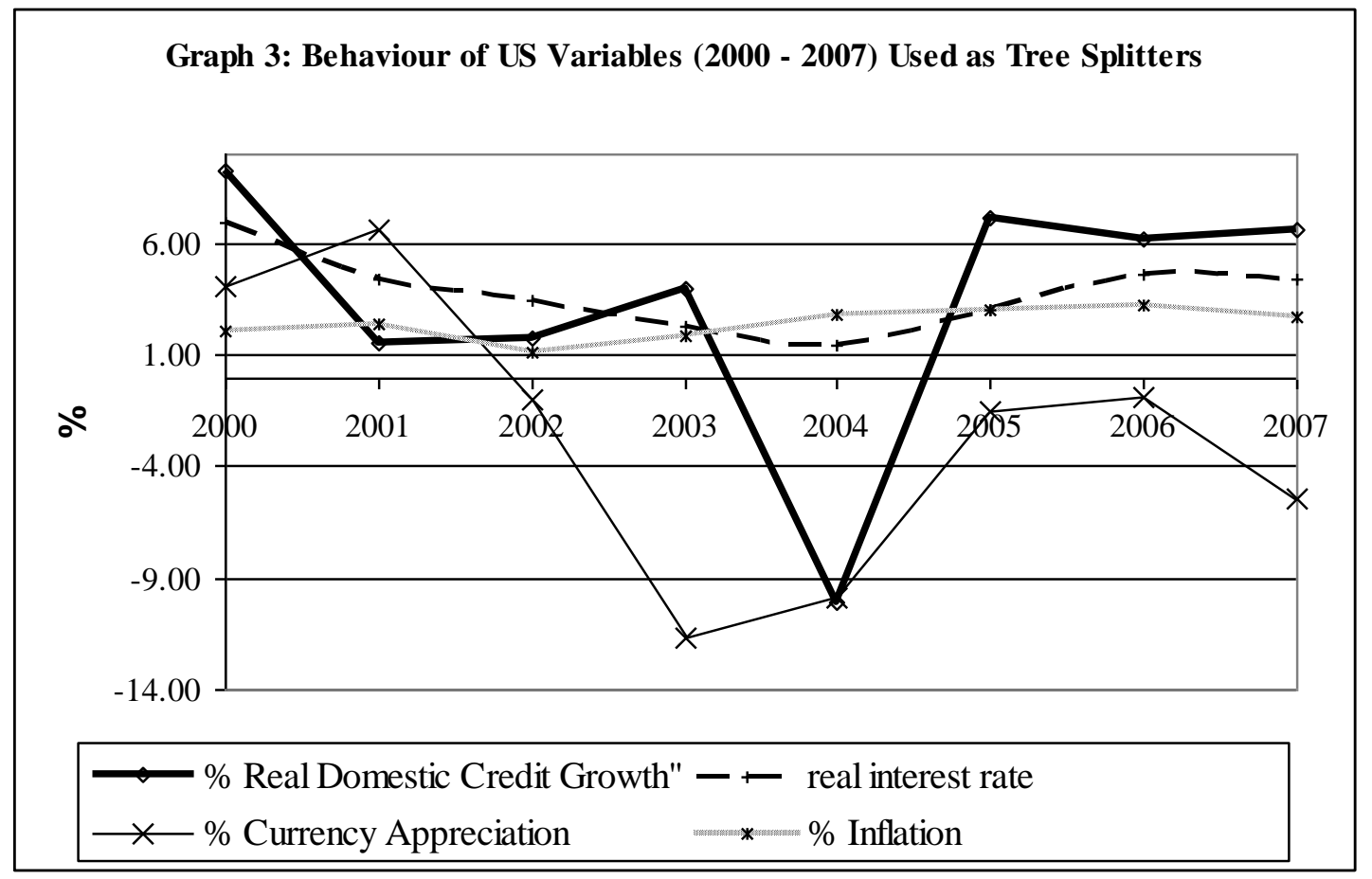

Third, the models highlight variables that are worthy of interest by the authorities even in qualitative macroprudential surveillance, while the BRT model is rich in detecting patterns that may precede crises. For example, although the actual model did not give a formal detection for 2007, it did highlight how low real interest rates plus currency depreciation can worsen crisis probabilities, as did in due course occur in the United States (see Graph 3).

Finally, the logit and BRT approaches are complementary. Applying both models to the same data yields different insights into banking crises: the logit model is able to generate confidence intervals for variables that are significant contributors to crises and can be used to compute the marginal changes to crisis likelihood when only one variable is varied whilst the BRT approach is better able to map the evolution of crises conditional on the co-movements of multiple variables.

\section{A checklist approach - generic features of financial instability and the sub-prime crisis}

Drawing on theory and experience, Davis (1995, 1999, 2003) identifies certain common features to all types of crisis, which are helpful in anticipating crisis events. 
Indeed, he argues that examination of the features of diverse financial crises, suggests that there are common generic patterns in advance of crises. Key aspects are:

- Regime shifts, first to laxity (such as deregulation) which provokes a credit cycle, later to rigour (e.g. monetary tightening) that triggers a crisis;

- Easing of entry conditions to financial markets, leading to heightened competition and risk taking;

- Debt accumulation and asset price booms, generating vulnerable balance sheets in the financial and non financial sectors;

- Innovation in financial markets, which increases uncertainty during the crisis; and

- Risk concentration and lower capital adequacy for banks, which reduces robustness to shocks.

He saw these as providing the most basic dataset of indicators common to crises ${ }^{11}$, acknowledging that many of these features have occurred separately without entailing a crisis, and indeed are part of the normal functioning of a market economy. It is their combination and acuteness (i.e. the degree of deviation from norms) that is crucial to the occurrence of financial instability. And many of them are encapsulated in financial soundness or macroprudential indicators.

As regards regime shifts to laxity, the monetary policy stance of most countries was relaxed from 2001 onwards, as policy sought to stimulate growth in the wake of the equity bear market in the absence of significant inflationary pressures. Underlying this was the additional regime shift of globalisation and the growth of China, the low price of whose goods helped to keep inflation low. In terms of risk of a regime shift to rigour, monetary tightening was indeed on the cards in 2007 owing to shrinking output gaps and higher energy prices, although it is harder to suggest that this feature actually triggered the crisis.

There was clearly an easing of entry conditions to financial markets, leading to heightened competition and risk taking. Easy financing of hedge funds is one example; another is the growth of SIVs and conduits to hold securitised assets, an innovation that facilitated entry. Furthermore, origination of lending to US sub prime households was often by non banks not previously active in that market.

Debt accumulation and asset price booms, generating vulnerable balance sheets in the financial and non-financial sectors; rises in debt of both the corporate and household sectors in the US and much of Europe took place over the mid 2000s, with prices of equities and real estate rising alongside. These were, as noted, potentially unsustainable and the more recent fall in asset prices combined with high debt has led to weak balance sheets and widespread defaults and insolvency.

Innovation in financial markets, which increases uncertainty during the crisis was a key aspect of the sub prime crisis. All financial innovations give rise to a risk of financial instability, because their behaviour in a period of turbulence is unknown. The innovation of structured products was by its nature likely to generate such uncertainty in extreme form given the opacity and difficulty of pricing the instruments

11 See also Demirguc Kunt and Detragiache (1998a and b) and Kaminsky (1999). 
even in good times, despite which they benefited from a liquidity premium as securities, while investors were apparently unconcerned with the principal agent problems which are fundamental to that innovation.

Risk concentration and lower capital adequacy for banks, which reduces robustness to shocks is the final indicator. Banks' risk adjusted capital ratios seemed sound in 2007, but the conduits and SIVs generated hidden difficulties for banks, as did warehousing risk with failure to dispose of loans by securitisation in a manner expected.

We contend that such a checklist would have been usefully applied to the sub prime crisis, capturing in particular an a priori suspicion of financial innovation as well as the new entry implicit in securitisation and sub prime lending. However, a weakness is that these factors had for the most part also been present for 2005 and 2006 also. The approach highlights vulnerability but needs supplementing in respect of possible triggers of a crisis by early warning models and detailed macroprudential analysis.

\section{Conclusion}

We have shown that the US sub-prime crisis was only partly foreseen by the policy community; although all had important insights, perhaps the BIS had the most forward looking analysis of events and possible policy responses, reflecting its longer term concern over the build-up of debt, risks in structured products and rising asset prices. Even they failed to see some of the consequences of the crisis, notably the seizing up of interbank markets. Among global early warning systems for the US and UK the logit performed best but was still only marginally able to help predict the crisis (although the BRT model had a higher average crisis prediction score). These results to some extent show that the sub prime crisis had specific features that were not typical of the average banking crisis in both advanced and emerging economies. However, we contend that rather than rejecting such models, the results how they should be better adapted for the specific features of advanced countries, that may also include aspects of securities market instability. That would be a step towards making them a useful supplement for macroprudential analysis. Equally, we maintain that a generic features checklist would also be useful complement for such analysis. 


\section{References}

Bank of England (2007), "Financial Stability Report, April 2007”, Bank of England, London

Bank for International Settlements (2007), “ $77^{\text {th }}$ Annual Report”, BIS, Basel.

Breiman, L., Friedman, J. H., Olshen, R. A. and Stone, J. C., (1984). "Classification and Regression Trees". Wadsworth Inc, Monterey, California.

Congdon, Peter (2003). “Applied Bayesian Modelling”. Wiley Series in Probability and Statistics, John Wiley and Sons Ltd.

Davis E P (1995), "Debt, financial fragility and systemic risk, revised and expanded version", Oxford University Press.

Davis E P (1999), "Financial data needs for macroprudential surveillance: what are the key indicators of risk to domestic financial stability?", Lecture Series No 2, Centre for Central Banking Studies, Bank of England.

Davis E P (2002), "A typology of financial crises", in Financial Stability Review No 2, Austrian National Bank.

Davis, E. Philip and Karim, Dilruba (2008). "Comparing Early Warning Systems for Banking Crises”. Journal of Financial Stability, Volume 4, Issue 2, pp 89 - 120.

Duttagupta, Rupa and Cashin, Paul (2008). "The Anatomy of Banking Crises". IMF Working paper series, No. 08/93, Washington, IMF.

Demirgüç-Kunt, Asli and Detragiache, Enrica (2005). "Cross-Country Empirical Studies of Systemic Bank Distress: A Survey." IMF Working Papers 05/96, International Monetary Fund.

Demirguc, Asli \& Detragiache, Enrica, (2000). "Monitoring Banking Sector Fragility: A Multivariate Logit Approach." World Bank Economic Review, Oxford University Press, vol. 14(2), pages 287-307, May.

Demirguc-Kunt, A. and Detragiache, E. (1998). "The Determinants of Banking Crises in Developed and Developing Countries". IMF Staff Paper, Vol. 45, No. 1, International Monetary Fund, Washington.

ECB (2007), “Financial Stability Review, June 2007”, European Central Bank, Frankfurt.

Ghosh, Swati and Ghosh, Atish R., (2002). "Structural Vulnerabilities and Currency Crises". IMF Working Paper No. 02/9, International Monetary Fund.

IMF (2007), “Global Financial Stability Report, April 2007”, International Monetary Fund, Washington DC 
Karim, Dilruba (2008 $)$. "The Optimal Threshold for Banking Crisis Prevention and the Consequences of Regulatory Forbearance". Brunel University Working Paper, 08 - 19, Department of Economics and Finance, Brunel University.

Karim, Dilruba (2008 $)$. "The Use of Binary Recursive Trees for Banking Crisis Prediction". Brunel University Department of Economics and Finance Working Paper, Brunel University.

Katz, M. (2006). "Multivariable Analysis: A Practical Guide for Clinicians”. New York: Churchill-Livingstone.

Manasse, Paolo, Roubini, Nouriel and Schimmelpfennig, Axel, (2003). "Predicting Sovereign Debt Crises". IMF Working Paper No. 03/221, International Monetary Fund.

Steinberg, D. and Colla, P., (1995). "CART: Tree Structured Non-Parametric Data Analysis”. Salford Systems, San Diego, California.

Steinberg, D. and Golovnya, M. (2007). "CART 6.0 User's Guide”. Salford Systems, San Diego, California. 


\section{Appendix}

Graph A.1: OECD Crisis Predictions by Logit and Tree Models: 2004 - 2006 Data

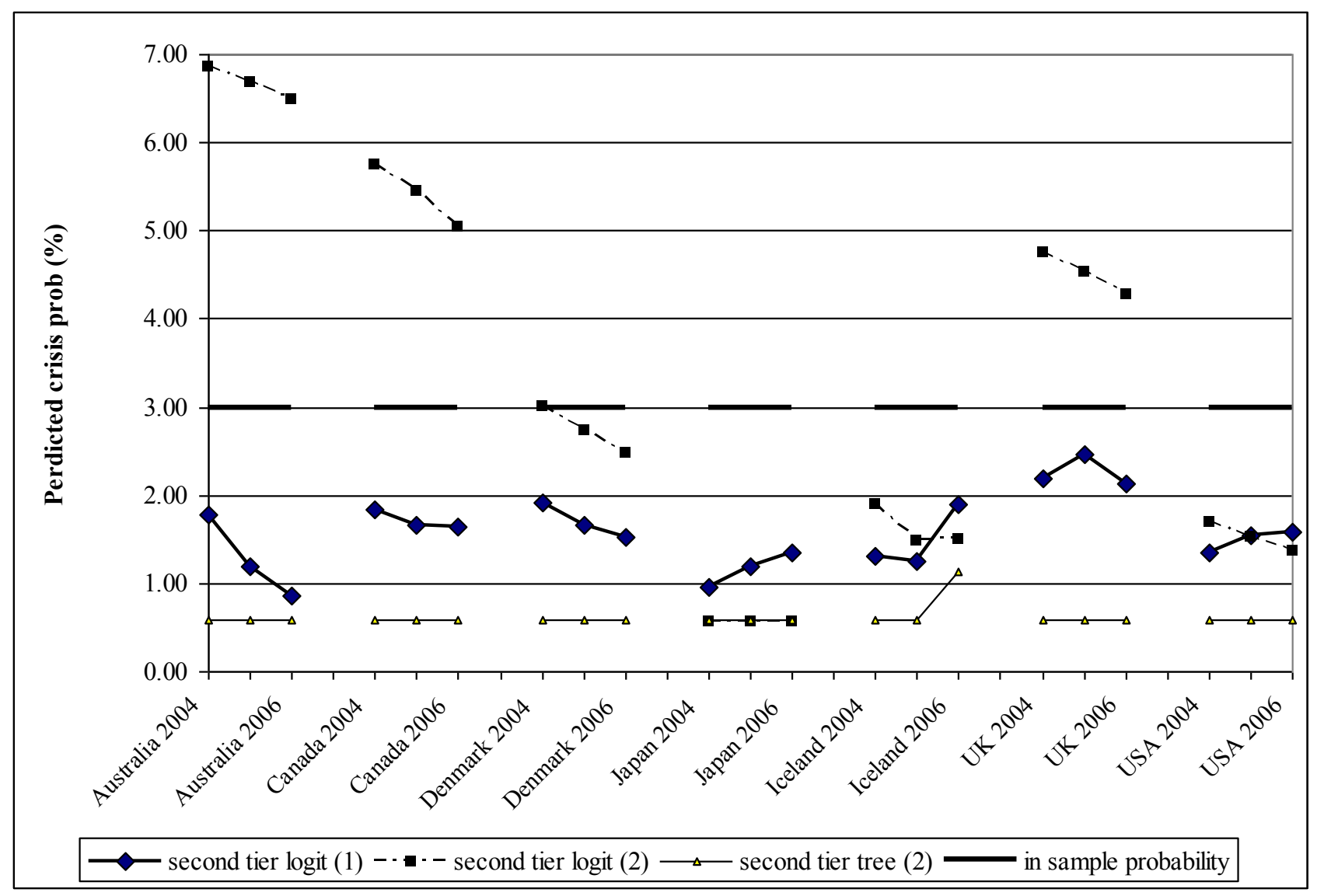


Table A.1: Banking Crisis Dates and Countries (Source Demirgüc Kunt and Detragiache 2005)

\begin{tabular}{|c|c|c|c|}
\hline Algeria & $1990-92$ & Madagascar & $1988-1991^{* *}$ \\
\hline Argentina & $\begin{array}{l}1980-82 \\
1989-90 \\
1995 \\
2001-2003\end{array}$ & Malaysia & $\begin{array}{l}1985-1988 \\
1997-2001\end{array}$ \\
\hline Burundi & $1994-1997^{* *}$ & Mali & $1987-1989$ \\
\hline Bolivia & $\begin{array}{l}\text { 1986-1988 } \\
\text { 1994-1997** } \\
2001-2002^{*}\end{array}$ & Mexico & $\begin{array}{l}1982 \\
1994-1997\end{array}$ \\
\hline Brazil & $\begin{array}{l}1990 \\
1994-99\end{array}$ & Nepal & $1988-1991^{* *}$ \\
\hline Cameroon & $\begin{array}{l}1987-1993 \\
1995-1998\end{array}$ & Niger & $1983-1986^{* *}$ \\
\hline Chile & 1981-1987 & Nigeria & 1991-1995 \\
\hline Congo (Rep of) & $1992-2002^{*}$ & Norway & 1987-1993 \\
\hline Colombia & $\begin{array}{l}1982-1995 \\
1999-2000\end{array}$ & PNG & $1989-1992^{* *}$ \\
\hline Costa Rica & $1994-1997^{* *}$ & Paraguay & $1995-1999$ \\
\hline Ecuador & $1995-2002^{*}$ & Peru & 1983-1990 \\
\hline El Salvador & 1989 & Philippines & $\begin{array}{l}\text { 1981-1987 } \\
\text { 1998-2002 }^{*}\end{array}$ \\
\hline Finland & 1991-1994 & Portugal & 1986-1989 \\
\hline Ghana & $\begin{array}{l}1982-1989 \\
1997-2002^{*}\end{array}$ & Senegal & 1983-1988 \\
\hline Guinea Bissau & $1994-1997^{* * *}$ & South Africa & 1985 \\
\hline Guyana & 1993-1995 & Sri Lanka & 1989-1993 \\
\hline Indonesia & $\begin{array}{l}1992-1995^{* * *} \\
1997-2002^{*}\end{array}$ & Sweden & 1990-1993 \\
\hline Israel & 1983-1984 & Swaziland & 1995 \\
\hline Italy & $1990-1995$ & Tanzania & $1988-1991^{* *}$ \\
\hline Jamaica & 1996-2000 & Thailand & $\begin{array}{l}1983-1997 \\
1997-2002^{*}\end{array}$ \\
\hline Japan & $1992-2002^{*}$ & Turkey & $\begin{array}{l}1982 \\
1991 \\
1994 \\
2000-2002^{*}\end{array}$ \\
\hline Jordan & 1989-1990 & Uganda & $1994-1997^{* *}$ \\
\hline Kenya & 1993-1995 & USA & 1980-1992 \\
\hline Korea & $1997-2002$ & Uruguay & $\begin{array}{l}1981-1985 \\
2002^{*}\end{array}$ \\
\hline Lebanon & $1988-1990$ & Venezuela & 1993-1997 \\
\hline
\end{tabular}

